\title{
Shifts in the distributions of pressure, temperature and moisture and changes in the typical weather patterns in the alpine region in response to the behavior of the North Atlantic Oscillation
}

\author{
Martin Beniston and Patricia Jungo \\ University of Fribourg, Switzerland
}

\begin{abstract}
An investigation has been undertaken in order to assess the manner in which the North Atlantic Oscillation (NAO) influences not only general, average, climatic conditions, but also the extremes of dynamic and thermodynamic variables. By choosing representative sites in the Swiss Alps, the present study shows that there is a high sensitivity of the extremes of the probability density functions of temperature, moisture and pressure to periods when the NAO index is either highly-positive or strongly negative. When the NAO index is strongly positive, temperatures and pressure shift towards positive anomalies, and there is a general reduction in atmospheric moisture at high elevations. Furthermore, a change in typical alpine winter weather patterns can be detected during strongly positive NAO anomaly phases. The winters of the last decade of the $20^{\text {th }}$ Century (1989-99) are characterized by a substantial decrease in cold advective high pressure situations and simultaneously an important increase in warm convective high pressure systems. These patterns differ significantly from the weather types, which have been recorded for earlier periods of the $20^{\text {th }}$ Century. As a result of the highly-positive nature of the NAO index in the latter part of the $20^{\text {th }}$ Century, it is speculated here that a significant part of the observed warming in the Alps results from the shifts in temperature extremes induced by the behavior of the NAO. These changes are capable of having profound impacts on snow, hydrology, and mountain vegetation.
\end{abstract}

\section{Introduction}

The North Atlantic Oscillation (NAO) is a large-scale alternation of atmospheric pressure fields (i.e., atmospheric mass), whose centers of action are near the Icelandic Low and the Azores High. One mode of the NAO is when sea-level pressure is lower than normal in the Icelandic low pressure center, it is higher than normal near the Azores, and vice-versa, hence the notion of an oscillatory behavior of the system. Another mode is that pressures may also rise or fall simultaneously in both centers of meteorological activity, but then the NAO signal is not quite as well-defined. The NAO index is a normalized pressure difference between the Azores (an alternate location is Lisbon, Portugal) and Iceland; it is a measure of the intensity of zonal flow across the North Atlantic and the associated position of storm tracks and regions of strongest storm intensity. This flow is itself driven by the temperature (and hence pressure) contrasts between polar and tropical latitudes.

The NAO represents one of the most important modes of decadal-scale variability of the climate system after ENSO (El Niño/Southern Oscillation), and accounts for up to $50 \%$ of sea-level pressure variability on both sides of the Atlantic (Hurrel, 1995). It is observed to strongly influence precipitation and temperature patterns on both the eastern third of North America and western half of Europe ; the influence of the NAO is particularly conspicuous during winter months. It has been shown in recent years (Beniston et al., 1994 ; Hurrel, 1995; Rodgers, 1997; Serreze et al., 1997) that a significant fraction of climatic anomalies observed on either side of the Atlantic are driven by the behavior of the NAO.

Beniston (2000), among others, has shown that temperature, moisture and pressure trends and anomalies at high elevations stand out more clearly than at lower levels, where boundary-layer processes, local site characteristics and urban effects combine to damp the large-scale climate signals. Climatic processes at high elevation sites can thus in many instances be considered to be the reflection of large-scale forcings, such as the NAO. These findings have been confirmed through numerical experimentation by Giorgi et al. (1997), who have underlined the altitudinal dependency of regional response to large-scale climatic forcings. 
A particular feature of the positive phase of the NAO index is that it is invariably coupled to anomalously low precipitation and milder than average temperatures, particularly from late fall to early spring, in southern and central Europe (including the Alps and the Carpathians), while the reverse is true for periods when the NAO index is negative. As an illustration of the impacts of NAO behavior on the seasonality and quantity of snow in the Alps, Beniston (1997) has shown that periods with relatively low snow amounts are closely linked to the presence of persistent high surface pressure fields over the Alpine region during late Fall and to early Spring; these fields are themselves well in phase with the NAO. Furthermore, since the mid-1980s and up until 1996, the length of the snow season and the general quantities of snow amount decreased substantially in the Alps, as a result of pressure fields which were far higher and more persistent than at any other time during the $20^{\text {th }}$ century (see for example Beniston, 1997).

Because of the exceptional nature of the NAO in the 1990s compared to other periods of the $20^{\text {th }}$ Century (in particular the record high values of the NAO Index observed in the 1990s, and the exceptionally long persistence of the index within the positive range), it is of interest to ascertain to what extent these conditions have determined the highly anomalous behavior of temperatures during the 1990s (Jungo and Beniston, 2001). In particular, it is important to assess the extent to which changes in the NAO are influencing not only average values of temperature or humidity, but also their extremes. This is done by investigating changes in the probability density functions (PDF) of climate variables. In the current debate on global warming, there is increasing awareness that shifts in climatic extremes in a changing climate are likely to impact more significantly on environmental and socio-economic systems than simply changes in means.

A further manner of investigating the relations between the behavior of the NAO and regional climates is through the analysis of typical weather types, using for example the climatological weather classification of Schüepp (1978), which was developed for the Alpine region. The Schüepp classification can be considered to be reliable for Swiss weather conditions, since it includes most of the significant elements that determine the atmospheric conditions over a certain region, i.e., pressure, origin and dynamics of an airmass, dominant wind direction, etc. The Schüepp classification is based on three main groups, namely convective, advective and mixed weather types, which are further subdivided in relation to the origin of the airmass and the pressure type. Thus 40 weather types emerge from the classification, where 15 are of a convective nature, 24 of an advective nature and 1 of mixed type, the latter occurring when the center of a depression is located just over the Alps. Analyzing the persistency of the European Circulation Types (Grosswetterlagen of Hess and Brezowsky) from 1881 to 1992, Wanner et al. (1997) have found out that the zonal flows increased considerably since 1965 and with them the persistence of almost all circulation types. They have also undertaken a short analysis on the persistency of Schüepp weather types, concluding that in an increasing tendency of the 5-day persistency of convective situations with high pressure has occurred in recent years.

\section{The influence of the NAO on Alpine climate}

\subsection{Influence on means}

\section{Insert Figure 1 here}

Figure 1 depicts the time series of the wintertime NAO index during the $20^{\text {th }}$ Century, and the associated surface wintertime (December-January-February) pressure anomalies in Zürich, based on the 30-year climatological average period 1961-1990; a 5-point filter has been applied to both curves in order to remove the higher-frequency fluctuations for the purposes of clarity. Here, wintertime refers to the values averaged for December, January, and February (DJF). Average pressure values, even at a single site, can be considered to be a measure of synoptic-scale conditions influencing the Alpine region, as discussed in Beniston et al. (1994). The pressure measured at Zürich or elsewhere, when averaged on a seasonal or longer time span, is therefore representative of the large-scale pressure field over Switzerland. The very close relationship between the two curves in Figure 1 highlights the subtle linkages between the large-scale NAO forcings and the regional-scale pressure response over Switzerland. When computed for 1901-1999, $56 \%$ of the observed pressure variance in Switzerland can be explained by the behavior of the NAO. From 1961-1999, this figure rises to $83 \%$, which is considerable bearing in mind the numerous factors which can determine regional pressure fields. Wanner et al. (1997) speculate that the persistent Alpine high pressure 
observed in the 1980s and early 1990s is linked to rising NAO index values through a northern shift of the polar front jet axis. When this occurs, the Alps lie to the right exit zone of the diverging jet streamlines, and are thus subject to mass influx and hence positive pressure tendencies.

\section{Insert Figure 2 here}

Figure 2 illustrates the relation between the wintertime NAO index and the DJF temperature time series for Zürich, where both curves are smoothed as in Figure 1. As for pressure trends, the synchronous behavior between temperature and the NAO is striking, particularly in the second half of the $20^{\text {th }}$ Century, where the minimum temperature variance which can be accounted for by the NAO fluctuations from 1961-1999 exceeds $72 \%$.

\subsection{The influence on the probability density functions of climate variables}

In order to highlight the possible relationships of high or low NAO index values with shifts in the frequency distributions of climate variables such as pressure, temperature and moisture, two thresholds for the wintertime NAO index have been chosen, namely the lower and upper 10 percentiles of the NAO index distribution during the $20^{\text {th }}$ Century (i.e., the $10 \%$ and $90 \%$ thresholds, which correspond roughly to index values around -1.5 and +2.0 , respectively). These thresholds are representative of two highly contrasting synoptic regimes affecting the Alps, namely above-average pressure and associated positive temperature and negative moisture anomalies when the threshold is above the $90 \%$ level, and lower than average pressure and its controls on temperature and humidity when the index is lower than the $10 \%$ level.

The probability density functions (PDF) of pressure, maximum and minimum temperatures, and relative humidity, have been computed for periods where the NAO index is $\geq 90 \%$ threshold, and the temperature PDFs for winters where the NAO anomaly index $\leq 10 \%$ threshold The discussion will focus on the highelevation site of Säntis, a summit in north-eastern Switzerland which culminates at 2,500 m above sea level (asl), and Zürich, located about $70 \mathrm{~km}$ to the west, at $569 \mathrm{~m}$ asl. The results presented for these two sites are representative of other high mountain and lower-elevation plain locations in Switzerland. The Säntis data are particularly interesting because the high altitude of this site implies that it is closer to free atmospheric conditions, where the data are less likely to be contaminated by local site features, urban effects or atmospheric boundary-layer influences commonly encountered at lower elevations. In addition, the Säntis climate record is available in digital form on a daily basis from 1901 and is one of the most homogenous data sets at high elevations available in the database of the Swiss Meteorological Service, MeteoSwiss (Bantle, 1989).

\section{Insert Figure 3 here}

Figures 3 illustrates the behavior of the pressure PDFs at Säntis, computed for periods of the $20^{\text {th }}$ Century where the NAO index exceeds the upper threshold $(90 \%)$, or is inferior to the lower threshold $(10 \%)$. A substantial shift towards significantly higher pressures is observed for periods when the NAO index exceeds the $90 \%$ threshold; the PDF curve is shifted to the right of the diagram, with a change in both the skewness and kurtosis of the distribution. Figure 4 depicts another manner of visualizing the shifts in the pressure PDF from a strongly negative NAO forcing to a highly positive one, namely by mapping the difference in the normalized distribution between high and low thresholds, at both Säntis and Zürich. A normalized distribution is defined here as the departure of pressure from its central value (i.e., the 50-percentile) in the range observed at the two sites. Using the normalized scale enables a direct comparison to be made, which would otherwise not be possible if the absolute pressure values were used, since the pressure difference between Zürich and Säntis is about $200 \mathrm{hPa}$. The response of the surface pressure extremes to a switch in the NAO index is observed to be a clear transfer from the lower tails of the pressure distribution to its upper tails. In fact, the central values of the PDF of pressure at both the low and the high elevation site appear to be a «pivotal point» around which the shift occurs. It is seen that the integral of less-than-average pressure is practically identical to that of higher-than-average pressure when the NAO index is positive. 


\section{Insert Figure 4 here}

The forcing of the NAO is thus reflected not just in terms of a change in mean pressure as illustrated in Figure 3 but, indeed, in terms of the entire pressure distribution itself. The changes are by no means negligible, and represent an average shift on the order of $20 \mathrm{hPa}$ at both Säntis and Zürich. When the NAO index at Säntis $\leq 10 \%$ level, over $15 \%$ of the winter months are concerned by pressures which are less than $730 \mathrm{hPa}$, while less than $10 \%$ are affected by pressures exceeding $750 \mathrm{hPa}$. When the NAO index $\geq 90 \%$ level, on the other hand, the respective figures change to $6 \%$ and $54 \%$.

Under such circumstances, it is not surprising that temperature distributions and the extremes of these distributions are also strongly influenced by the behavior of the NAO. Figure 5 shows the response of the minimum temperature PDF to these two thresholds.

Figure 5 illustrates the shift in the normalized winter minimum temperature distribution as a function of low and high index thresholds for both Säntis and Zürich. Similar to the shifts in pressure PDF illustrated in Figure 4, transfers from the extreme low to the extreme high tails of the distribution occur around a « pivotal point » which is at the center of the range of minimum temperatures. The changes are substantial at Säntis, from a peak frequency at about $12^{\circ} \mathrm{C}$ below the center of the PDF range when the NAO threshold is low, to about $7^{\circ} \mathrm{C}$ above the central part of the range when the NAO threshold is high. Comparable shifts in the PDF anomalies are also observed at Zürich ; the respective peak frequencies occur for anomalies of $-10^{\circ} \mathrm{C}$ and $+5^{\circ} \mathrm{C}$,respectively, around the central part of the range of the Zürich Tmin distribution. In other words, the extreme low tails of the minimum temperature distribution disappear during periods of high NAO index, in favor of much warmer temperatures. Temperatures below $-15^{\circ} \mathrm{C}$ at Säntis, which account for roughly $30 \%$ of the winters where the NAO index $\leq 10 \%$ level, are present only $15 \%$ of the DJF months for high NAO values, i.e., the periods with extreme cold conditions are reduced by $50 \%$. Conversely, temperatures at the upper end of the distribution, for example above $-5^{\circ} \mathrm{C}$ represent $12 \%$ of the winter days for low NAO values and $23 \%$ for high NAO values. The duration of milder temperatures at Säntis is thus almost doubled under conditions during which a high NAO index prevails.

\section{Insert Figure 5 here}

Similar conclusions can be reached for the distribution of Tmax (Figure 6). This particular figure emphasizes the fact that the number of days in winter in which maximum temperatures exceed the freezing point range from 10 days for the lowermost NAO 10-percentile to 25 days for the uppermost NAO 10percentile. This obviously has implications for physical variables such as snow amount and duration, and biologically-relevant factors such as the start of the vegetation period, as will be mentioned later. Temperatures below the "pivotal point » of $-5^{\circ} \mathrm{C}$, which make up 48 days per winter during low NAO index episodes, drop sharply to only 33 days when the index is high.

\section{Insert Figure 6 here}

\section{Insert Figure 7 here}

Moisture and precipitation in the Alpine region is also influenced by the behavior of the NAO. As an illustrative example, Figure 7 shows the difference in the distribution of relative humidity at Säntis for the two selected thresholds. In the case of the negative index threshold, over $50 \%$ of the values recorded in winter exceed $90 \%$ relative humidity, while in the case of the positive threshold, the $90 \%$ relative humidity is exceeded only during $35 \%$ of the winter months. There is thus a clear reduction in ambient moisture at high elevations. Such a substantial drying of the atmosphere is not observed at the lower elevations exemplified by the Zürich observational site; this is because low elevation sites are located within a much moister boundary-layer which, in winter, is often characterized by fog or stratus below 800-1200 m asl when high pressure conditions prevail. The lower levels are essentially decoupled from the higher atmosphere (see for example Beniston and Rebetez, 1996), and as a consequence, the sensitivity of relative humidity to changes in the NAO index is much lower than at higher elevations. 
Indeed, the influence of local particularities of climate at low elevations in Switzerland are reflected in Table 1 , which expresses the changes in the mean of the PDFs of four variables considered in this study (minimum and maximum temperatures, relative humidity, and precipitation). It is seen that the range of the shift in means is consistently larger at Säntis than at Zürich, whatever the climate variable considered.

Although only illustrated here for two sites representative of low and high elevations, respectively, the conclusions from Table 1 hold for other locations in Switzerland, according to their elevation, i.e., the sensitivity of climatic variables at low elevations to shifts in the sign of the NAO index is systematically lower than at higher elevations.

\subsection{The influence on climatological weather types over the alpine region}

In a first approach, 5 periods of weather types with an 11-year span (1945-55, 1956-66, 1967-77, 1978-88, 1989-99) are compared. This allows to assess whether the weather types also undergo a change as abrupt as that exhibited by temperature, or if there is a smooth change subsequent to 1970, where the positive NAO tendencies markedly increased and became more in phase with surface pressure at Zürich (Figure 1).

A second point of interest concerns the weather types during the 1990s, taking into account only the extreme 10-percentiles of minimum and maximum winter temperatures, hereafter defined as "coldest and warmest winter nights and days". Figure 4 shows that the winter days become warmer during a phase of extreme positive NAO anomalies. Together with the shift in extreme temperatures, it is seen that during the 1990s, the number of coldest winter nights and days is decreasing while the number of warmest days is increasing. It is thus of interest to determine whether the change in the frequency distribution of extremes can also be detected in terms of weather types in addition to the NAO index. Using the methodology developed by Jungo and Beniston (2001), the $10^{\text {th }}$ and the $90^{\text {th }}$ percentiles of winter minimum and maximum temperature anomalies are based on the climatological mean period (1961 to 1990). The statistics are carried out for the mean time series of 3 groups of stations, representing the low altitudes north of the Alps, the Alpine high altitudes and the low altitudes south of the Alps.

\section{Insert Figure 8 here}

Figure 8 depicts the frequency of each weather type during 5 sets of winter seasons. There is a clear increase in the frequency of convective situations with high pressure. This weather type has doubled its frequency during the last period (1989-99) compared to the previous periods. As mentioned in Wanner et al. (1997) the 5-day persistency of this weather type also tends to increase. Evident as well is the sharp decrease of eastern advective situations, generally associated with high pressure or situations with reduced pressure gradients (spatially uniform pressure fields), reflecting the typical "Bise" situation, characterized by clear skies, very cold easterly winds and strong infrared radiation loss at night. The western advective situations, with low or uniform pressure have always been numerous and do not change over the different periods considered. However, since 1989 they are seen to be the most frequent advective situations occurring in wintertime, along with the southwesterly low pressure weather type. The mixed type, where the low-pressure center of a depression is located over the Alps, is practically non-existent in the latter part of the period analyzed. The frequency of the climatological weather types during the last decade of the $20^{\text {th }}$ century is quite different to earlier periods. The recent evolution shows that during winter, warm westerly and southwesterly low pressure systems under advective conditions and, particularly, high-pressure systems under convective conditions have increased at the expense of cold, high pressure systems under advective conditions.

\section{Insert Figure 9a and $9 b$ here}

Figure 9a illustrates the fact that the coldest winter nights have diminished since 1945, but most occurrences are related to the cold "Bise" situation, i.e., eastern advective situations with high or uniform pressure. After about 1995 there is a slight tendency however, for a shift from eastern to northeastern situations. The 3 sets of regions have further in common that all southern advective situations and the mixed situation, where the 
low-pressure center of a frontal systems is located over the Alps, no longer occur after 1990. Figure 9b shows a general increase in the number of warm winter nights towards the end of the $20^{\text {th }}$ century. These occur most frequently during westerly and southwesterly advective situations under low pressure, particularly north of the Alps and in the south at low elevations. At high altitudes, the convective situations with high pressure are the most frequent cause for mild temperatures. In all regions, according to the weather classification analysis, the higher number of warm nights is principally related to an intensification of convective situations. This intensification is limited to high-pressure systems at high altitudes (clear skies), whereas at low altitudes north of the Alps, it is more related to low pressure systems (covered skies).

\section{Insert figure $9 \mathrm{c}$ and $9 \mathrm{~d}$ here}

In figure 9c it is seen that just as the coldest winter nights, the coldest winter days occurred since 1945 predominantly during cold "Bise" situations. This pattern does not change after 1990, although at high altitudes a slight shift from easterly to northeasterly situations are to be seen. Due to the diminishing number of coldest winter days, the number of weather types after 1990 are limited to just a few types. The cold easterly advective high pressure systems are frequent, especially at low altitudes north of the Alps and at high altitudes. Furthermore, at northern low altitudes the high pressure convective types, and at high altitudes, the uniform pressure convective types (covered skies) are rather frequent for coldest winter days. At southern low altitudes the weather types of the coldest winter days are more diverse. Frequent next to the cold eastern advective situation are high and uniform pressure convective systems, western and advective high pressure systems originating from west, northwest, southwest and south. The influence of the NAO is not clearly visible on the weather types of the coldest winter days.

Figure $9 \mathrm{~d}$ shows that the number of warm winter days exceeding the $90 \%$ distribution threshold increases, principally at low altitudes north of the Alps, as well as at high altitudes. The increase in the warmest winter days, which occur under conditions of westerly advective flow and low pressure, begins in the 1970s and the intensification of convective high pressure situations since 1990 is an additional sign of the dominant influence of the NAO on Alpine climates, particularly since the 1970s.

\section{Discussion}

In the last decade, much interest has focused on the North Atlantic Oscillation, and it is sometimes used as an empirical predictor for precipitation and temperature in regions where climatic variables are well correlated with the NAO index. This is clearly seen to be the case in Northern and Southern Europe, Central Europe and the Alps being generally a pivot around which the forcing of the NAO is amplified with distance north or south of the alpine region. While at low elevations, the NAO signal may be weak or absent in the Alps, higher elevation sites are on the contrary sensitive to changes in NAO patterns (Beniston et al., 1994 ; Beniston and Rebetez, 1996 ; Rebetez and Beniston, 1998 ; Hurrell, 1995 ; Hurrel and van Loon, 1997 ; Giorgi et al, 1997). The processes associated with periods when the NAO index exceeds the $90 \%$ level include frequent blocking episodes, where pressure fields over the Alpine area are high, and vertical circulations induce subsiding air with associated compressional warming. Such circulations invariably generate positive temperature anomalies, and reductions in moisture and precipitation. In addition, diurnal warming at high elevations is enhanced by above-average sunshine, since there is a lowering of cloud amount and duration during periods of blocking high pressures. The reverse is generally true for periods when the NAO index is below the 10-percentile of its distribution. It could be argued that nocturnal cooling should also be stronger in a cloud-free atmosphere, thus leading to lower minimum temperatures; however, in complex terrain, radiative cooling at night will lead to downslope flow and accumulation of cold air in the valleys. The nocturnal cooling effect is, proportionally, not as strong at mountain summits such as Säntis as further down in the valleys.

Such anomalies are not only reflected in the means of the analyzed climatic variables, but also - and perhaps especially - in their extremes. The previous section has shown that there are clear links between strongly positive or negative modes of the NAO, and extremes of pressure, temperature, and moisture ; high NAO values systematically shift the distributions from the lower extremes to the upper extremes. 
Since the early 1970s, and up to 1996, the wintertime NAO index has been increasingly positive, indicative of enhanced westerly flow over the North Atlantic. This has led to synoptic situations in recent decades which have been associated with abundant precipitation over Norway, as cyclonic tracks enter Europe relatively far to the north of the continent (Hurrell, 1995). Over the Alpine region, on the other hand, positive NAO indices have resulted in surface pressure fields that have been higher than at any time this century. Investigations by Beniston et al. (1994) concluded that close to $25 \%$ of pressure episodes exceeding the $965 \mathrm{hPa}$ threshold recorded this century in Zürich (approximately $1030 \mathrm{hPa}$ reduced sea-level pressure) occured in the period from 1980 - 1992, with the four successive years from 1989 - 1992 accounting for $16 \%$ of this century's persistent high pressure in the region.

\section{Insert Table 2 here}

Table 2 shows an analysis of mean wintertime values for minimum and maximum temperatures, relative humidity and precipitation at Säntis for four distinct periods of the $20^{\text {th }}$ Century, namely 1901-1999, 19501999, 1975-1999, and 1989-1999. In each case, the observed DJF mean is given, followed by the mean which would have occured without the influence of highly-positive NAO index (beyond the 90-percentile threshold). The third column for each variable represents the bias which NAO index $\geq 90$-percentile has imposed on temperature and moisture variables. It is seen in this Table that the bias is relatively small when considering the entire $20^{\text {th }}$ Century (1901-1999), but then increases as one approaches the end of the $20^{\text {th }}$ Century. In the last decade, from 1989-1999, the bias for minimum temperatures exceeds $1^{\circ} \mathrm{C}$. In the absence of the large forcings imposed by NAO index values $\geq 90$-percentile, this decade would in fact have been slightly cooler in terms of minimum temperature than the average conditions which prevailed from 1975-1999. Indeed, had there not been such a strong positive NAO forcing in the latter years of the $20^{\text {th }}$ Century, minimum temperatures would not have risen by almost $1.5^{\circ} \mathrm{C}$ (decadal mean for the $1990 \mathrm{~s}$ minus century mean from 1901-1999) but by less than $0.5^{\circ} \mathrm{C}$, as seen in the second column of the minimum temperature analyses. The bias imposed by strongly-positive NAO thresholds on maximum temperatures follows the same trends, but is not as high as for minimum temperatures; even in the absence of the NAO forcing, maximum temperatures would have risen substantially in the latter part of the $20^{\text {th }}$ Century.

In terms of moisture, relative humidity has decreased in winter, with a bias of close to $10 \%$ in the period 1989-1999, resulting from the NAO forcing; mean DJF relative humidity would have otherwise remained relatively constant throughout the century. Precipitation is also seen to be considerably marked by the NAO forcing in the last decade of the $20^{\text {th }}$ Century, with a substantial drop of $20 \%$ of winter precipitation linked to the high and persistent NAO index recorded during this period.

Because over half of the NAO index values exceeding the 90-percentile have occurred since 1985, it may be concluded that the NAO is a significant driving factor for the climatic anomalies observed in recent years in the Alps. In particular, the highly anomalous nature of temperatures and their extremes that have been observed and discussed in Jungo and Beniston (2001) are largely explained by the large-scale influence on regional climate generated by the recent trends of the NAO. Removal of the biases imposed by high NAO episodes would have resulted in relatively modest increases in minimum temperatures and reduced rates of maximum temperature warming, thus leading to Alpine-scale warming comparable to global-average warming (Jones et al., 1999).

With the analysis of the Schüepp (1978) weather type classification from 1945 to 1999, divided into five 11year periods, it has been shown that the frequency of weather types changed rather abruptly during the period 1989-1999. The changes are principally due to an important increase in high-pressure convective systems and an important decrease in cold "Bise" (easterly high-pressure) situations. The most important winter weather types during the last decade of the $20^{\text {th }}$ century were western and southwestern advective situations with low pressure (covered skies) and convective situations under high pressure (clear skies). These are all warm winter weather types, clearly influenced by the strong and persistent positive NAO signal during this period, and certainly one cause of the abrupt shifts of the winter minimum and maximum temperature towards more positive values during the period 1989-1999. The shift is very strong at high altitudes because of the large increase of convective high-pressure situations, which generate anomalously mild weather in the Alps. 
The frequencies of the coldest and warmest winter nights and days (previously defined as the 10- and 90percentile thresholds of temperature) in different regions in Switzerland also exhibit close relations to the NAO index. The most evident influence is found at low altitudes north of the Alps and at high altitudes within the mountains themselves. The number of cold winter days and nights with temperatures below the $10 \%$ threshold decreases towards the end of the $20^{\text {th }}$ century. Paradoxically, since the early 1970 s, the rather warm westerly advective weather type with low pressure is more frequently linked to the coldest winter days and nights. This weather type, as well as the southwesterly low pressure type are, for more obvious reasons, associated with the warmest winter nights since the 1970s; a more recent feature is the influence of convective weather types since 1990, which also exert a determining influence on the warmest winter nights. The number of warmest winter days with temperatures above the $90 \%$ threshold increased principally at low altitudes to the north and at high altitudes after 1990. Warm days occurring during the rather cold winter weather types associated with easterly advective situations have always been rare, but they disappeared completely after 1990. For these warm winter days, high-pressure convective weather types have increased in frequency since 1990, and also the westerly and southwesterly advective systems since about 1978.

\section{Conclusions}

In the context of climatic change forced by enhanced greenhouse-gas concentrations, the anomalously warm winters experienced in recent years have been shown to be driven in large part by the high values of the NAO index which has prevailed in the last 15 years of the $20^{\text {th }}$ Century.

The influence of these high values has been to increase the upper tails of the temperature and pressure probability density functions to a significant degree, and to reduce the relative humidity and precipitation amounts at high elevations. Because of the controls which the NAO can exert over much of the winter season, the combination of higher temperatures and lower moisture is likely to have a number of impacts on the natural environment. In particular, the fact that at high elevations such as Säntis $(2,500 \mathrm{~m}$ asl), the number of days where diurnal temperatures exceed the freezing point can increase by as much as two weeks during the winter season inevitably has implications for the timing of snow-melt and the amount of snow which remains on the ground throughout the winter. Earlier snowmelt in turn feeds into the hydrological systems, by increasing river discharge earlier in the season compared to «normal» or negative NAO indexes. Warmer temperatures are also associated with liquid rather than solid precipitation falling at higher elevations; when combined with early snowmelt runoff, this can lead to critical hydrological situations, particularly downstream of the mountains, as was experienced for example in early 1995, when the Rhine River overflowed its banks in Germany and The Netherlands.

Less snow and warmer conditions have taken their toll of glacier mass in the Alps, while at the same time in the late 1980s and early 1990s, Norwegian glaciers were advancing because of the excess precipitation in northerly latitudes associated with high NAO indexes. Earlier snow-melt can also trigger the seasonal cycle of mountain plants, as much of the high Alpine vegetation is dependent on snow-pack amount and duration for its metabolic cycles. The reduction of snow amount, which is closely related to the higher NAO indexes, and generally warmer average temperatures, are coincident with an upward migration of plant species, as reported by Grabherr et al. (1994) and Keller et al. (2000). Plants which survive under warmer conditions are progressively invading areas in which only cold-resistant vegetation was present until recently.

It would be difficult to draw more far-reaching conclusions for climate impacts on the basis of the short series of anomalously warm winters experienced in the Alps; this is inter alia the case for ecosystem responses to climate change, which generally occur over longer time-scales. The run of mild winters in the Alps associated with high NAO index values has, however, had a measurable effect on snowline altitude, snow amount and duration, which in turn has influenced flow regimes in a number of hydrological basins originating in the mountains. Perturbations to hydrological regimes in a changed climate will certainly be the norm in the $21^{\text {st }}$ Century (e.g., Gleick, 1987; Krenke et al., 1991; Leavesly, 1994), because of the different timings of the beginning and end of the snow season, and the overall reduction in the duration of the mountain snow-pack. The sparsity of snow has also had significant economic impacts on Swiss mountain communities in the late 1980s and early 1990s, which are largely dependent on winter sports for 
their income. The conclusion that snow amount and duration has been sensitive to changes in climate since 1985 at altitudes below $1500-2000 \mathrm{~m}$ is consistent with the rise in average snowline projected under a warmer global climate (IPCC, 1996); these conclusions could already help certain communities in preparing adaptation strategies for the future, for example through diversification of tourism activities rather than relying solely on the ski industry in winter. The conclusions presented here could provide guidance for future environmental and economic planning in the Alps, particularly for activities related to winter tourism, water resource management, and ecosystem studies.

Because of the very significant controls of the NAO on regional climate variables, their means and their extremes, it is vital in the current debate on global warming for general circulation climate models to improve their performance in simulating North Atlantic decadal-scale variability. This would enable an assessment of whether such variability will be as large as during the $20^{\text {th }}$ Century, or whether the system will exhibit systematically positive NAO index values as observed since the $1980 \mathrm{~s}$. This would enable climate modelers and climate-impacts specialists to quantify the role of the future behavior of the NAO on climatic extremes in Europe. It is recognized by the IPCC $(1996,1998)$ that there is now a crucial need by the climate impacts community for climate scenario data which is not only at high spatial resolution, but which includes information on extremes. Extremes, and not changes in means, generally have the strongest bearing on environmental disruption and damage. The conclusions reported in this paper clearly point to the need for more research in order to improve the simulations of the NAO in climate models, and our understanding of the underlying causal mechanisms of the oscillation, since it is without question one of the major controling factors on regional climate in the Alps.

\section{Acknowledgements}

The authors would like to thank the anonymous reviewers whose comments have helped improved the original manuscript. Financial support by the Swiss National Science Foundation for one of the authors (Patricia Jungo) is gratefully acknowledged; this funding is linked to contract 20-56732.99.

\section{References}

Bantle, H., 1989: Programmdokumentation Klima-Datenbank am RZ-ETH Zürich, Swiss Meteorological Institute, Zürich.

Beniston, M., 1997: From Turbulence to Climate. Springer, Heidelberg and New York, 330 pp.

Beniston, M., 2000: Environmental Change in Mountains and Uplands. Arnold/Hodder and Stoughton/Chapman and Hall Publishers, London, UK, and Oxford University Press, New York, USA. $172 \mathrm{pp}$.

Beniston, M., and Rebetez, M., 1996: Regional behavior of minimum temperatures in Switzerland for the period 1979 - 1993. Theor. and Appl. Clim. 53, 231 - 243

Beniston, M., Rebetez, M., Giorgi, F., and Marinucci, M. R., 1994: An analysis of regional climate change in Switzerland. Theor. and Appl. Clim., 49, 135 - 159

Giorgi, F., Hurrell, J., Marinucci, M., and Beniston, M., 1997: Height dependency of the North Atlantic Oscillation Index. Observational and model studies. J. Clim., 10, $288-296$

Gleick, P.H., 1987: Methods for evaluating the regional hydrologic impacts of global climatic changes, J. Hydrology, 88, 97-116.

Grabherr, G., M. Gottfried, and H. Pauli, 1994: Climate effects on mountain plants, Nature, 369, 448.

Hurrell, J. W., 1995: Decadal trends in the North Atlantic Oscillation regional temperatures and precipitation. Science, 269, 676 - 679

Hurrell, J. W., and van Loon, H., 1997 : Decadal variations in climate associated with the North Atlantic Oscillation. Climatic Change, 36, 301-326

IPCC, 1996: Climate Change. The IPCC Second Assessment Report. Cambridge University Press, Cambridge and New York. Volumes I (Science), II (Impacts) and III (Socio-economic implications)

IPCC, 1998: The regional impacts of climate change. Cambridge University Press, Cambridge and New York, $517 \mathrm{pp}$.

Jones, P.D., New, M., Parker, D.E., Martin, S. and Rigor, I.G., 1999 : Surface air temperature and its changes over the past 150 years. Reviews of Geophysics, 37, 173-199 
Jungo, P., and Beniston, M., 2001 : Changes in 20th century extreme temperature anomalies at Swiss climatological stations located at different latitudes and altitudes. Theor. and Appl. Clim. In press.

Keller, F., Kienast, F., and Beniston, M., 2000: Evidence of the response of vegetation to environmental change at high elevation sites in the Swiss Alps. Regional Env. Change, 2, 70-77

Krenke, A.N., G.M. Nikolaeva, and A.B. Shmakin, 1991: The effects of natural and anthropogenic changes in heat and water budgets in the central Caucasus, USSR, Mountain Res. Devel., 11, 173-182.

Leavesley, G.H., 1994: Modeling the effects of climate change on water resources - A review, Assessing the Impacts of Climate Change on Natural Resource Systems, K.D. Frederick, and N. Rosenberg, (eds.), Kluwer Academic Publishers, Dordrecht, 179-208.

Rebetez, M., and Beniston, M., 1998: Changes in sunshine duration are correlated with changes in daily temperature range this century. An analysis of Swiss climatological data. Geophys. Res. Letters, 25, 3611-3613

Rogers, J. C., 1997: North Atlantic storm track variability and its association to the North Atlantic Oscillation and climate variability of Northern Europe. J. Climate, 10, 1635-1647

Serreze, M. C., Carse, F., Barry, R. G., and Rogers, J. C., 1997: Icelandic low cyclone activity: Climatological features, linkages with the North Atlantic Oscillation, and relationships with recent changes in the Northern Hemisphere circulation. J. Climate, 10, 453-464

Schüepp, M., 1978: Klimatologie der Schweiz, Band III in: Beiheft zu den Annalen der Schweizerischen Meteorologischen Anstalt: Zürich. 89pp.

Wanner, H., Rickli, R., Salvisberg, E., Schmutz, C., and Schuepp, M., 1997: Global climate change and variability and its influence on Alpine climate - Concepts and observations. Theor. and Appl. Climatology, 58, 221-243 
Variable

$\operatorname{Tmin}\left[{ }^{\circ} \mathrm{C}\right]$

$\operatorname{Tmax}\left[{ }^{\circ} \mathrm{C}\right]$

Relative Humidity [\%]

Precipitation [mm/day]
Zürich

0.3

0.1

$-0.6$

$-0.4(-12.8 \%)$
Säntis
1.3
1.1
$-4.7$
$-0.9(-14.7 \%)$

Table 1: Differences in the means of the PDFs of pressure, minimum and maximum temperature, and relative humidity, at Zürich and Säntis, between periods when the NAO index $\leq-1.5$ and $\geq+2.0$

\begin{tabular}{|c|c|c|c|c|c|c|}
\hline \multirow{2}{*}{ Period } & \multicolumn{3}{|c|}{$\operatorname{Tmin}\left({ }^{\circ} \mathbf{C}\right)$} & \multicolumn{3}{|c|}{$\operatorname{Tmax}\left({ }^{\circ} \mathbf{C}\right)$} \\
\hline & $\begin{array}{c}\text { Observed } \\
\text { Mean }\end{array}$ & $\begin{array}{c}\text { Mean without } \\
\mathrm{NAO} \geq 90 \% \\
\text { level }\end{array}$ & Bias & $\begin{array}{c}\text { Observed } \\
\text { Mean }\end{array}$ & $\begin{array}{c}\text { Mean without } \\
\text { NAO } \geq 90 \% \\
\text { level }\end{array}$ & Bias \\
\hline 1901-1999 & -8.95 & -9.03 & 0.08 & -4.33 & -4.42 & 0.10 \\
\hline 1950-1999 & -8.66 & -8.74 & 0.13 & -3.36 & -3.55 & 0.19 \\
\hline 1975-1999 & -8.20 & -8.38 & 0.18 & -2.74 & -2.95 & 0.21 \\
\hline 1989-1999 & -7.50 & -8.56 & 1.06 & -2.15 & -2.50 & 0.34 \\
\hline \multirow[t]{2}{*}{ Period } & \multicolumn{3}{|c|}{ Relative Humidity (\%) } & \multicolumn{3}{|c|}{ Precipitation (mm/day) } \\
\hline & $\begin{array}{l}\text { Observed } \\
\text { Mean }\end{array}$ & $\begin{array}{c}\text { Mean without } \\
\text { NAO } \geq 90 \% \\
\text { level }\end{array}$ & Bias & $\begin{array}{c}\text { Observed } \\
\text { Mean }\end{array}$ & $\begin{array}{c}\text { Mean without } \\
\text { NAO } \geq 90 \% \\
\text { level }\end{array}$ & Bias \\
\hline 1901-1999 & 75.70 & 76.06 & -0.36 & 7.04 & 7.10 & $-0.06(-0.79 \%)$ \\
\hline 1950-1999 & 73.44 & 66.76 & 6.69 & 6.42 & 5.81 & $0.60(+9.41 \%)$ \\
\hline 1975-1999 & 69.14 & 69.71 & -0.56 & 6.73 & 6.90 & $-0.17(-2.54 \%)$ \\
\hline 1989-1999 & 65.82 & 75.34 & -9.52 & 8.12 & 9.76 & $-1.63(-20.1 \%)$ \\
\hline
\end{tabular}

Table 2: Mean DJF values for minimum temperature, maximum temperature, relative humidity and precipitation for different periods of the $20^{\text {th }}$ Century. The first column represents the mean recorded during each period; the second column represents the mean which would have been observed in the absence of NAO forcing beyond the 90-percentile threshold; the third column represents the bias imposed by NAO index values beyond this threshold (difference between the first two columns). 


\section{Figure Captions}

Figure 1: $20^{\text {th }}$ Century time series of the wintertime (DJF) NAO index and surface pressure anomalies at Säntis (2,500 m above sea-level). A 5-point filter is used to eliminate high-frequency oscillations in the series

Figure 2: As Figure 1, except for series of NAO and DJF minimum temperatures

Figure 3: Probability density function of pressure at Säntis for periods when the negative and positive NAO index thresholds are exceeded

Figure 4: Differences in the normalized probability density functions of pressure between periods where the NAO index $\leq-1.5$ and $\geq+2.0$, for Zürich (569 $\mathrm{m}$ above sea-level) and Säntis

Figure 5: As Figure 4, except for minimum temperature

Figure 6: Differences in the probability density function of maximum temperature (absolute values) between NAO index $\leq-1.5$ and $\geq+2.0$ (shown here for Säntis only)

Figure 7: As Figure 3, except for relative humidity

Figure 8: Frequency of the 40 alpine weather types of Schüepp (1978) from 1945 to 1999, divided into five periods of 11 years. The numbers printed into the figure indicate the exact frequency of the weather types, which show the most important changes in time (black bars). The five single bars of the convective weather type are, from left to right: high or spatially uniform pressure, followed by types originating in the west, north, east, and south. The three bars of each advective type indicate high, uniform or low pressure.

Figure 9: Evolution of the 40 alpine weather types of Schüepp (1978) from 1945 to 2000 in different regions of Switzerland for: a) coldest winter nights, b) warmest winter nights, c) coldest winter days, d) warmest winter days. 


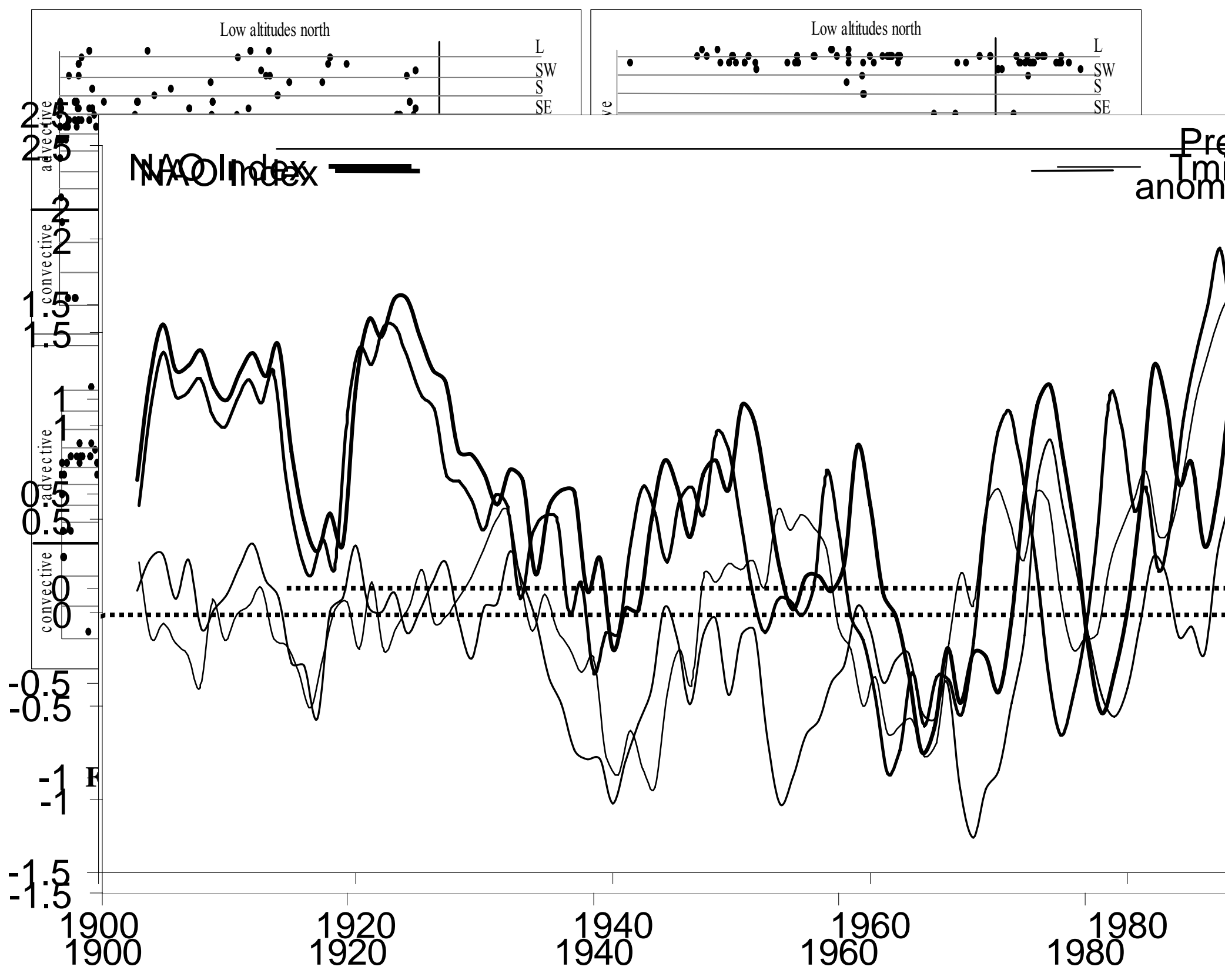

Figure 2 


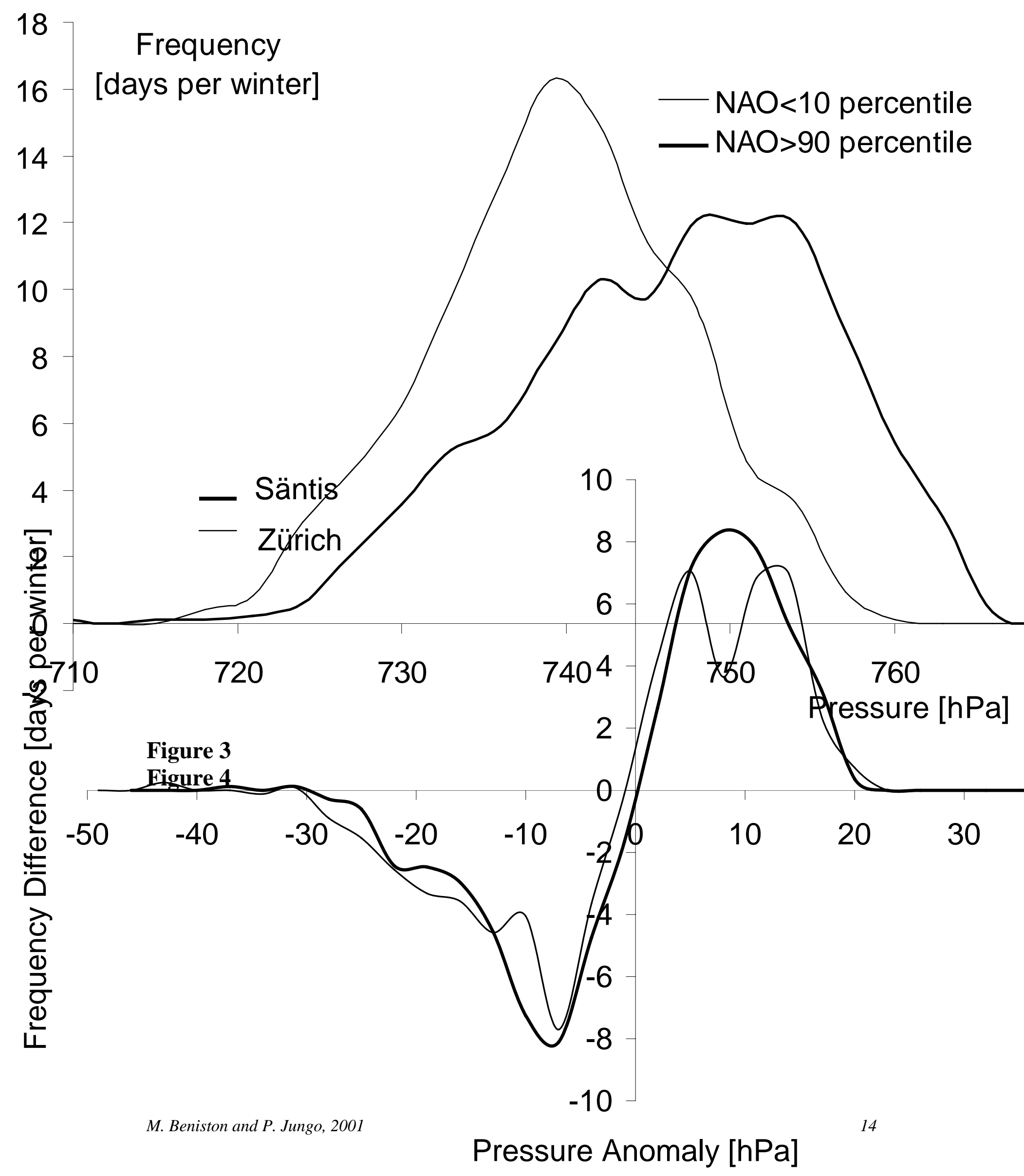




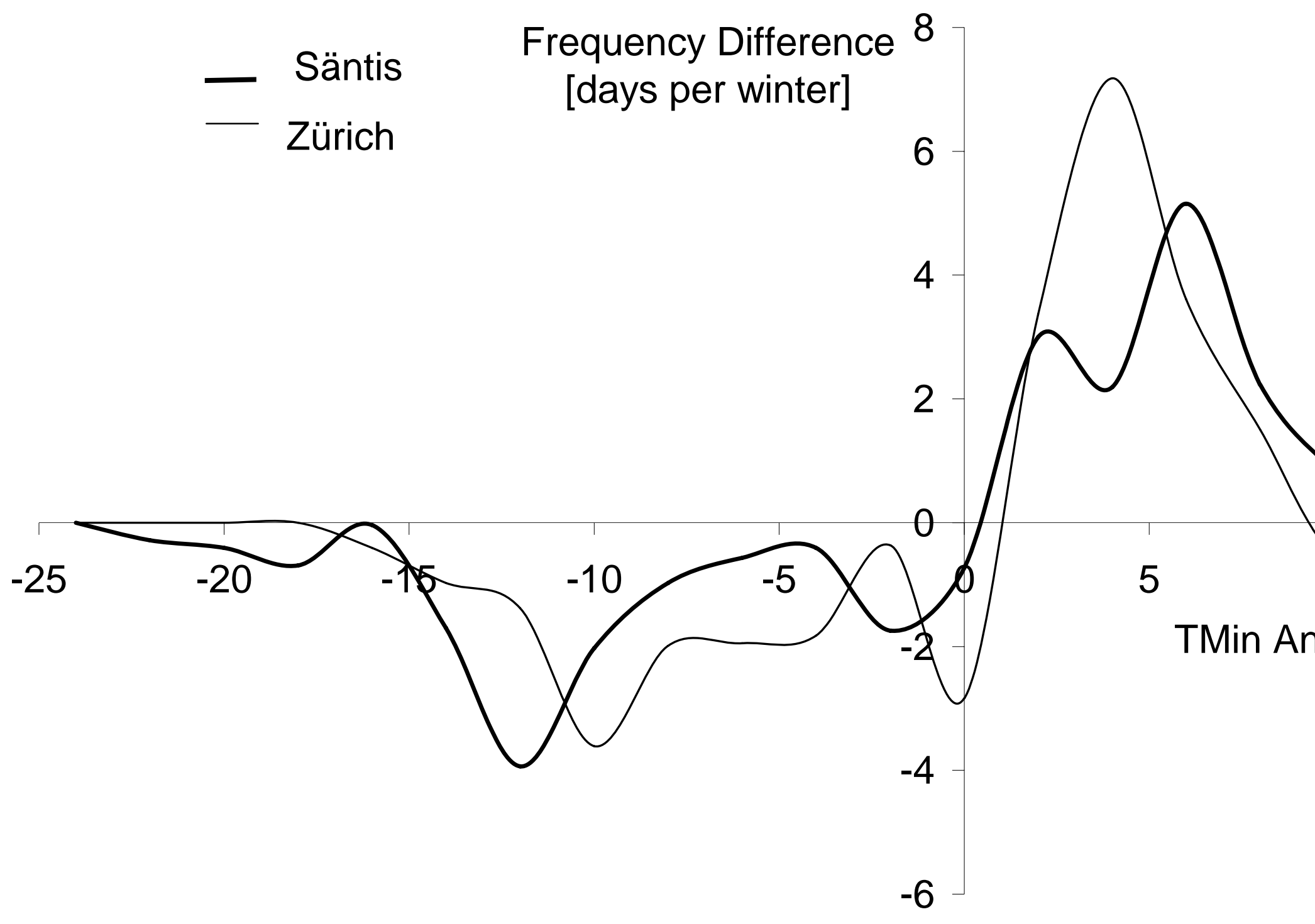

Figure 5 


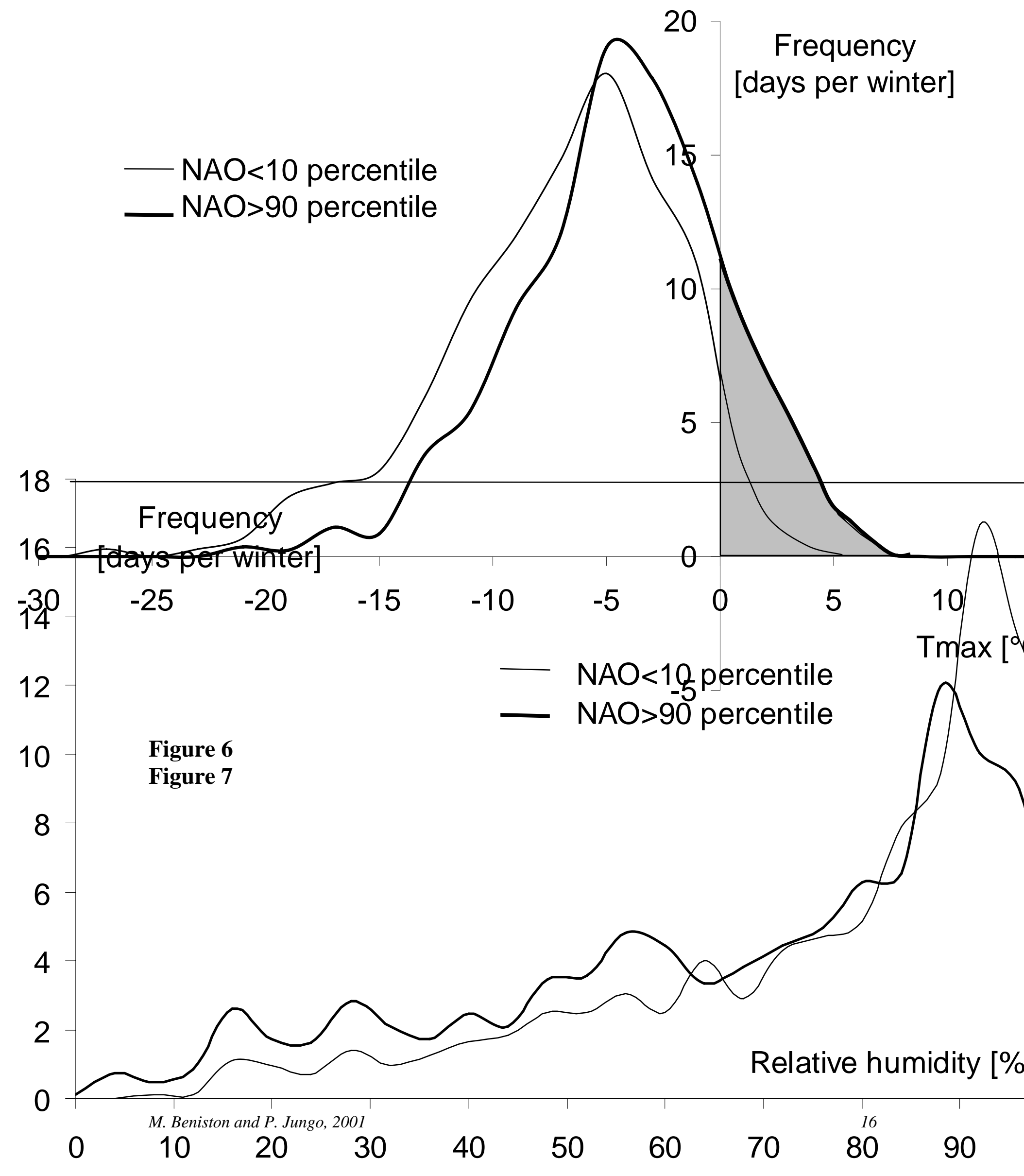




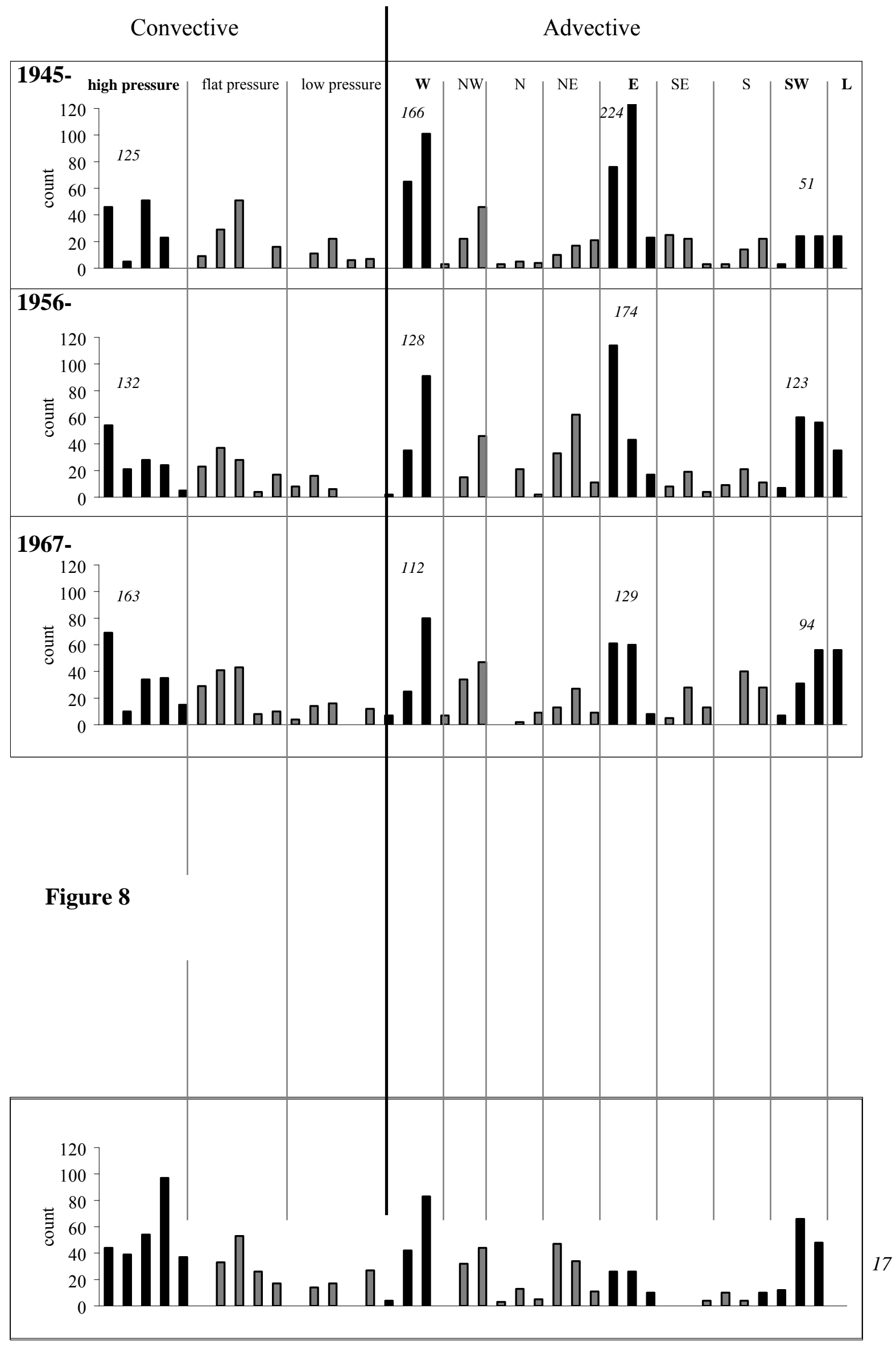

